\title{
Numerical study of mechanism of fold formation in a laminated rock
}

\author{
P K SAini ${ }^{1}$, T Kumar ${ }^{1}$, T N Singh ${ }^{2, *}, \mathrm{~N} \mathrm{Singh}^{1}$ and V K Keshri ${ }^{1}$ \\ ${ }^{1}$ Department of Mining Engineering, Institute of Technology, Banaras Hindu University, Varanasi 221 005, India. \\ ${ }^{2}$ Department of Earth Sciences, Indian Institute of Technology, Bombay, Powai 400 076, India. \\ ${ }^{*}$ Corresponding author. e-mail: tnsingh@iitb.ac.in
}

A set of large deformation experiments are presented to simulate folding pattern at various energy states during formation. In order to numerically simulate this phenomenon, a rectangular layer of shale is generated and compressed at various strain rates. The results reveal the variation in distribution of stress along the length of the bed. The stress distribution during elastic behaviour of shale bed at low compression rate and the change in stress distribution leading to rupture at high compression rates is discussed. Wavelength, limb length, bulk shortening, stress distribution, displacement of particles along the length of the bed is considered for comparative study of the fold pattern generated at various compression rates. The nature and position of crack generated during the formation of fold is also explained. After rupture in shale bed, the generation of fault and stress distribution in limbs of fold sliding over one another is also described.

\section{Introduction}

Folds are wavy undulations, which are developed in the country-rocks whenever the region is subjected to high pressure or stress. They are mainly displayed in stratified formations such as layered sedimentary rocks. Therefore, to simulate the effect of compression rate on folding pattern, a shale rock horizon is considered.

While carrying out analysis of folding, there are two main problems, one deals with mechanics of folding and the other is the causes of folding. Mechanics of folding involves internal changes that take place in a mass of strata that is being folded and stress and strain play a significant role (Carreras 2001; Enrique and Griera 2011).

Folds can be classified as tectonic or non-tectonic in origin. Those of tectonic origin results more or less directly from the forces originating within the outer cell of the earth and those of non-tectonic origin are largely results of movement under the influence of gravity near the surface of the earth (Schueller et al 2005). Horizontal compression, horizontal tension, intrusions of magma, intrusion of salt and vertical forces of unspecified origin are the main tectonic processes. In this study, horizontal compression is taken as the cause of folding. Contraction theory and continental drift are the two main theories proposed to explain the reasons of forces developing horizontal compression. Both theories propose that folds are generated as a result of strong compressive forces.

In order to simulate the natural condition considered in the above theories, forces are applied parallel to the bedding plane by moving a wall inward from one side and a resisting compressional force is applied by a fixed wall on other side of the stratum.

Keywords. Discrete element method; particle flow code; folding; bulk shortening; compression rate. 


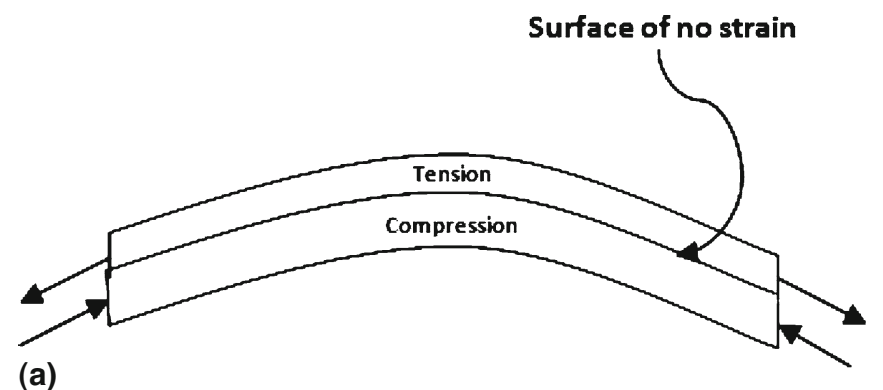

(a)

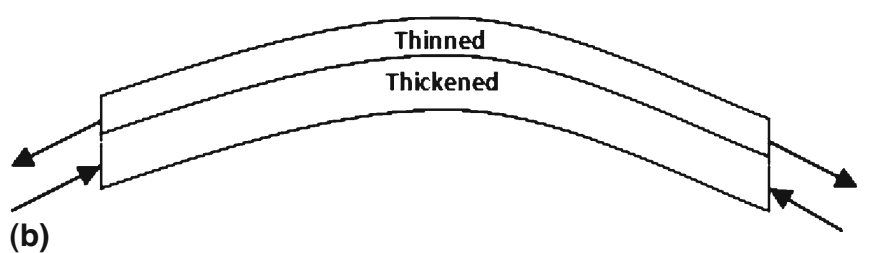

Figure 1. (a) Stresses in bent beam. (b) Deformation entirely plastic.

In any individual unit of fold, whether concave or convex, upwards folding, it is possible to imagine a plane which divides the fold into two halves as symmetrically as possible. Such an imaginary plane of symmetry of any fold is described as its axial plane (Ghosh 1993). In some folds, the axial plane is vertical; in others it may be inclined or horizontal. If the axial plane is curved, the dip or strike or both may differ from place to place. A number of research studies (Biot 1959, 1961; Biot et al 1961; Ramberg 1963; Smith 1975, 1977, 1979; Fletcher
1977, 1979) clearly explained that the shape and wavelength of folds potentially provide one of the few sources of direct information on rock rheology under natural conditions. In this work, limb length and wavelength of the fold pattern generated at various compression rates are investigated.

To simulate the deformation of the single homogeneous layer, a rigid boundary condition is required to model under $\mathrm{PFC}$ code. The part on the convex side is subjected to tension whereas the part on the concave side is subjected to compression. Between these two layers, there is an intermediate surface of no strain (figure 1). If, the bed is sufficiently ductile, it will yield plastically. On the convex side, it will lengthen and become thin but on concave side it will shorten and thicken. If it is brittle, it will yield by rupture. Tension fractures form on convex side whereas small thrust folds form on the concave side. This phenomenon has been thoroughly studied by many researchers using field, physical simulation in laboratory as well as numerical simulation (Carreras 2001; Schopfer and Zulauf 2002; Enrique and Griera 2011).

In the case of sedimentary rocks, some beds are competent whereas others are incompetent. A competent bed is strong and can transmit the compressive force much faster than a weak incompetent bed. Competency is influenced by various factors. Uniaxial compressive strength and massiveness of the formation are few important factors. A 2-m thick shale layer is considered in order to maintain optimum massiveness for fold simulation
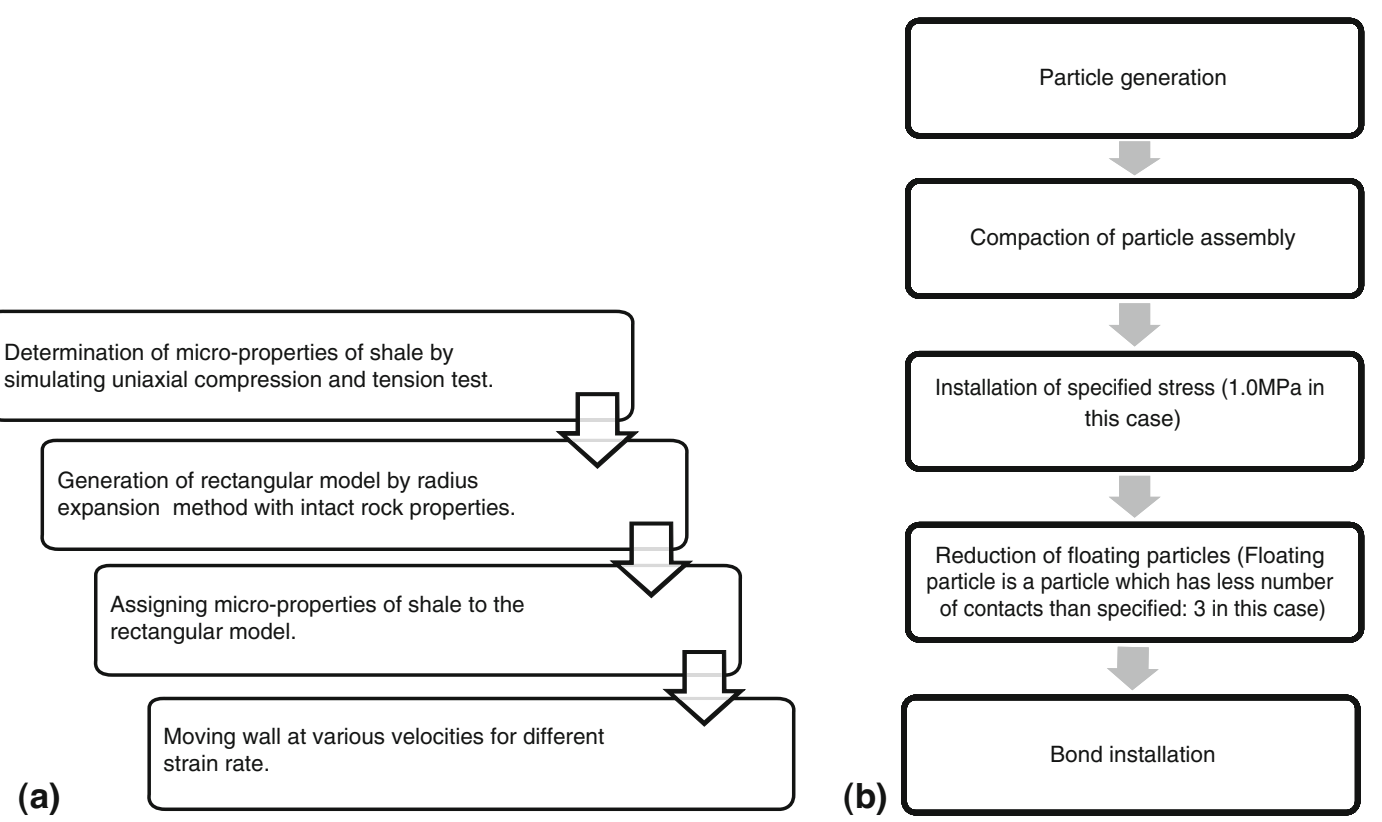

Figure 2. (a) Flowchart showing steps of model generation. (b) Standard steps followed by PFC2D to simulate uniaxial compression test. 
under rigid boundary conditions. This assumption is necessary and important to hold the micro-balls intact within single layer and prevent upward and downward flow to simulate the model material. If a stratum fails by rupture, it is no longer competent to transmit a compressive force.

In the present work, two-dimensional particle flow code (PFC2D) tool is applied for the simulation which is based on discrete element method of modelling (DEM). DEM, as introduced by Cundall and Strack (1979), explains the mechanical behaviour of assemblies of discs (2D) and spheres (3D). The method is based on the use of an explicit numerical scheme in which the interaction of particles is monitored contact by contact and the motions of the particle are modelled particle by particle. The micro-properties of rock are generated by inverse modelling procedure in PFC2D.

\section{Generation of model}

Discrete element method treats the problem domain as an assemblage of distinct, interacting bodies or blocks that are subjected to external loads and expected to undergo significant motion with time. PFC2D uses force-displacement law to specify the interaction between deformable intact rock blocks and law of motion, which determines the displacements induced in the blocks by outof-balance forces. The steps involved in generation process are shown in figure $2(\mathrm{a})$.

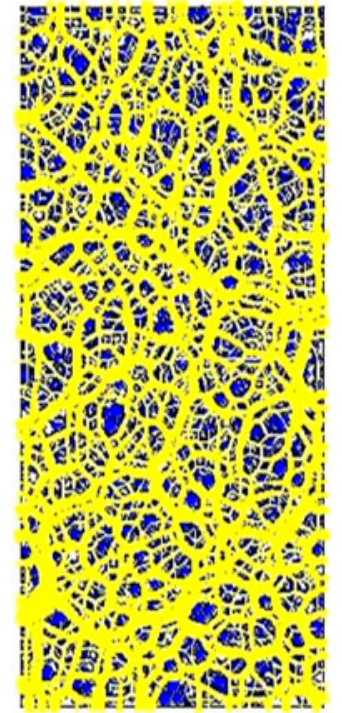

(a)

\subsection{Determination of micro-properties}

As the rock mass is laced with discontinuities, the accurate simulation of discontinuity properties to represent real rock mass is tedious and difficult. Before the generation of model, appropriate rock properties are required that can exhibit very close results to the in-situ rock mass. PFC2D simulates the mechanical behaviour (both static and dynamic) of material which is represented by circular particles either bonded or unbonded.

$\mathrm{PFC} 2 \mathrm{D}$ requires micro-mechanical properties of material to be generated. These properties are given in table 1 . To calibrate and verify the micro-mechanical properties of intact rock, 'Inverse modelling procedure' is adopted. This procedure simulates laboratory testing environment for rock samples. A uniaxial compression and tensional testing environment is simulated to determine the micro-properties of intact shale and sandstone. This simulation takes micro-properties as input and gives macro-properties like Young's modulus, Poisson's ratio, uniaxial compressive strength, tensile strength, etc., as output which are matched

Table 1. Micro-properties for particles used to generate shale bed.

\begin{tabular}{lc}
\hline Parameters & Values for shale \\
\hline Minimum ball radius $(\mathrm{cm})$ & 0.75 \\
Ball size ratio & 1.66 \\
Wall normal stiffness multiplier & 1.1 \\
Ball density $\left(\mathrm{kg} / \mathrm{m}^{3}\right)$ & 1800 \\
Ball-ball contact modulus $(\mathrm{GPa})$ & 1.45 \\
\hline
\end{tabular}

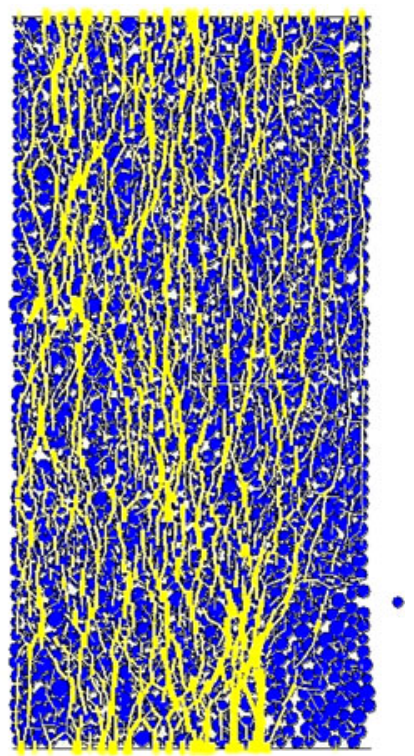

(b)

Figure 3. Shale sample (a) before loading and (b) after loading. 
Table 2. Comparison of mechanical properties obtained from numerical simulation of biaxial and Brazilian tests and from laboratory experiments for shale.

\begin{tabular}{lcc}
\hline Mechanical properties & $\begin{array}{c}\text { Mechanical properties } \\
\text { obtained from } \\
\text { numerical modelling }\end{array}$ & $\begin{array}{c}\text { Mechanical properties } \\
\text { obtained from } \\
\text { laboratory experiments }\end{array}$ \\
\hline Uniaxial compressive strength $(\mathrm{MPa})$ & 11.85 & 11.829 \\
Elastic modulus $(\mathrm{GPa})$ & 1.69 & 1.705 \\
Poisson's ratio & 0.281 & 0.27 \\
Tensile strength $(\mathrm{MPa})$ & 1.748 & 1.739 \\
\hline
\end{tabular}

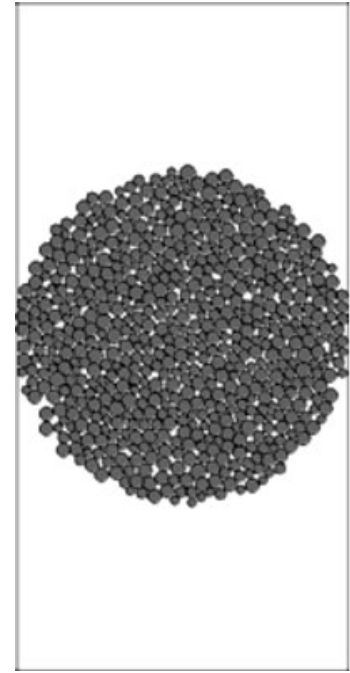

(a)

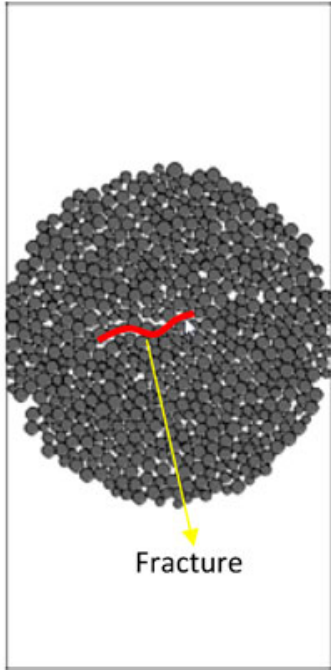

(b)

Figure 4. Trimmed sample generated for simulation of tensile testing of shale sample. (a) Sample before testing and (b) sample after loading.

to laboratory results to calibrate the accurate micro-properties of intact rock.

A particle flow code representation of a cylindrical intact rock sample bounded in a rectangular region is demonstrated in figure 3(a). Circular particles with specified statistical size distribution are bounded in four rigid walls. These particles were generated by specimen genesis procedure built in PFC2D. Parallel bond models were used to develop bonds among balls (PFC Manual, 1999a). PFC2D adopts following standard steps to simulate uniaxial compression test on rock samples (figure $2 \mathrm{~b}$ ).

To simulate loading in uniaxial compression test on cylindrical sample, top and bottom walls are moved towards each other by same velocity. Test is initiated at zero confining pressure to obtain stress-strain curve for the sample so that it can be calibrated with laboratory testing results of uniaxial compressive strength. Sample before and after loading is shown in figure 3( $a$ and $b$ ) respectively. It can be observed that the compressive strength is approximately similar to the laboratory results (table 2) which establishes/ validates the competence of micro-properties assigned to the particles and parallel bonds.

\subsubsection{Yellow chain exhibits contact forces}

To simulate tensile strength test scenario for intact rock sample, the rectangular assembly was trimmed to a circular disc of the diameter of cylindrical sample. In this test, top and bottom walls are moved towards each other with same velocity to load the trimmed sample (figure 4).

It is difficult to match both strengths (compressive and tensile strength) because the ratio of the tensile strength to compressive strength obtained in a bonded-particle model is approximately 0.12 , which is slightly higher as compared with the most hard rocks where the ratio is typically reported as near $0.08-0.10$. 


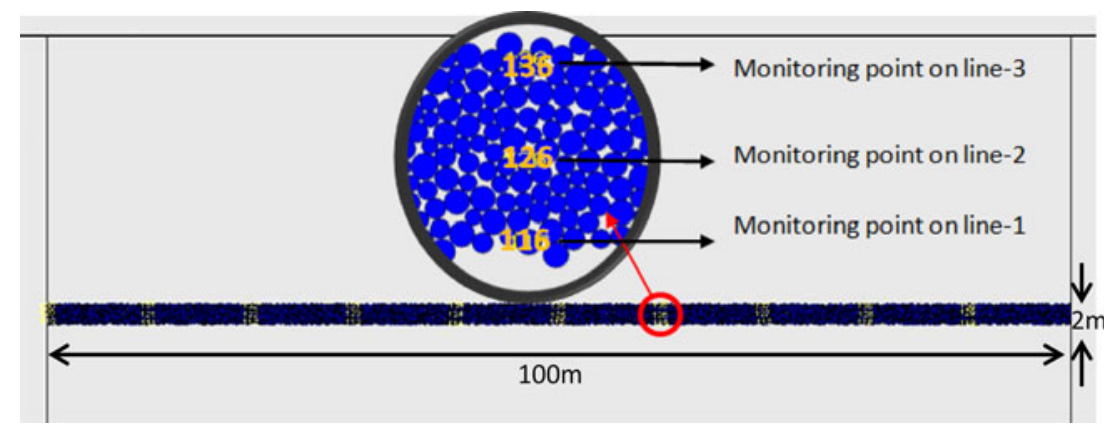

Figure 5. Rectangular model showing location of monitoring points.

\section{Generation of rectangular model}

A rectangular model of $100 \mathrm{~m}$ length and $2.0 \mathrm{~m}$ width is generated using radius expansion method in $\mathrm{PFC} 2 \mathrm{D}$. A total of 26,872 particles having radii $0.75-1.245 \mathrm{~cm}$, bounded by four boundaries were generated. This assembly of particles is demonstrated in figure 5.

After generation of rectangular model, the micro-properties calculated by the above procedure are assigned to the model. The upper and lower walls were deleted, keeping side walls intact (figure 5).

\section{Results and discussion}

The study of fold generation is carried out considering two main aspects, the cause of folding and mechanics. A rock structure approximating a shaly layer, made up of assembly of balls, is confined by two side walls. One of the two side walls (left wall) is moved inward to provide compressive force acting parallel to stratum. The other wall provides resisting force to the unit. The wall is moved at various velocities representing different compression rates. Most of the velocity rates simulated are higher to understand the phenomena and behaviour of rock at high stress zone line squeezing phenomenon which are very likely in the Himalayan mobile belts. It is obvious that these higher velocities are not possible in other areas during the formation of folds.

The mechanics of folding is discussed by taking into account the variation of stresses along the

Figure 6. Fold pattern in shale bed with no initial geometric perturbation at compression rate of $1 \mathrm{~mm} / \mathrm{s}$. length of the bed, vertical displacement of particles, and fractures developed during the formation of bed. For obtaining the details of stress and displacement, some monitoring points are defined along the length of the bed. Three lines are taken with each having 10 monitoring points on it. One of the lines is midway along the bed and other two are $0.8 \mathrm{~m}$ apart on either side of this mid-line. Starting from the left wall, points are defined on each line at an equal interval of $10 \mathrm{~m}$. The monitoring points are shown in the figure 5 .

The monitoring points are defined by marking a fixed identity number to balls in the bed. The displacement and stresses acting on these balls during the process of folding are stored in computer memory.

To study effect of variation in compression rate on folding in shale bed, the left wall is moved inward at speed of 1, 20, 50, 70 and $100 \mathrm{~mm} / \mathrm{s}$ for same time period in each case. The evaluation of fold and generation of stresses in each case is discussed separately.

\subsection{Folding pattern when left wall is moved at the rate of $1 \mathrm{~mm} / \mathrm{s}$}

Horizontal stress applied by the side wall displaces balls near the left wall by $0.21 \mathrm{~m}$. Therefore, a bulk shortening of $0.21 \%$ is obtained. The pattern of fold thus obtained is shown in figure 6 . A crest and a trough are generated in the originally horizontal stratum.

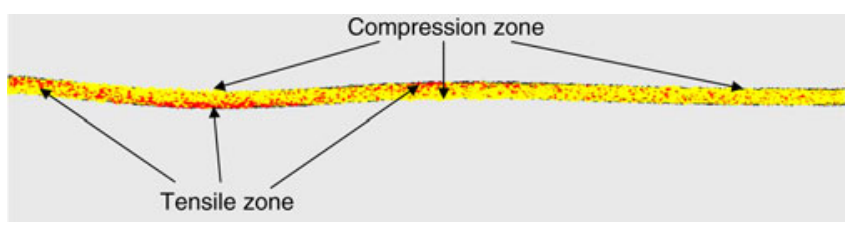

Figure 7. Distribution of compressive and tensile zone along the length of the bed at compression rate of $1 \mathrm{~mm} / \mathrm{s}$. 
Both compressive and tensile forces develop along the curvature of the bed. These forces induce stress within the bed. The maximum compressive stress is found on concave side while the maximum tensile stress is concentrated on convex side. Since the stresses between these two opposing maxima vary linearly, a plane exists between them where there is no bending stress. The locus of these points is known as neutral axis. The area under compressive region is shown in yellow while that in tension is shown in red (figure 7).

Von Kármán and Tsien (1939) proposed the two dimensional equation to describe the large deflection in the thin plates which is given below. Chekhov (1975) and Guz and Chekhov (1975) have also used the same equation for describing the linearized theory of fold formation in the large earth crust.

$$
\begin{gathered}
\frac{E h^{3}}{12\left(1-v^{2}\right)} \Delta^{2} \zeta-h \frac{\partial}{\partial x_{\beta}}\left(\sigma_{\alpha \beta} \frac{\partial \zeta}{\partial x_{\alpha}}\right)=P, \\
\frac{\partial \sigma_{\alpha \beta}}{\partial x_{\beta}}=0,
\end{gathered}
$$

where $E=$ Young's modulus, $\sigma_{\alpha \beta}=$ stress tensor, $h=$ thickness of the plate, $\zeta=$ out of plane deflection, $v=$ Poisson's ratio, $P=$ external normal force per unit area of the plate, and $\Delta=2$-dimensional Laplacian.

Introducing Airy stress function $\chi$, the above equations become

$$
\begin{aligned}
& \frac{E h^{3}}{12\left(1-v^{2}\right)} \Delta^{2} \zeta-h \\
& \times\left(\frac{\partial^{2} \chi}{\partial y^{2}} \frac{\partial^{2} \zeta}{\partial x^{2}}+\frac{\partial^{2} \chi}{\partial x^{2}} \frac{\partial^{2} \zeta}{\partial y^{2}}-2 \frac{\partial^{2} \chi}{\partial x \partial y} \frac{\partial^{2} \zeta}{\partial x \partial y}\right)=P, \\
& \Delta^{2} \chi+E\left\{\frac{\partial^{2} \zeta}{\partial x^{2}} \frac{\partial^{2} \zeta}{\partial y^{2}}+\left(\frac{\partial^{2} \zeta}{\partial x \partial y}\right)^{2}\right\}=0 .
\end{aligned}
$$

For the pure bending of thin plates the equation of equilibrium is $D \Delta^{2} \zeta=P$, where

$$
D=E h^{3} / 12\left(1-v^{2}\right) .
$$

Table 3. Stress distribution along the length of the bed at compression rate of $1 \mathrm{~mm} / \mathrm{s}$.

\begin{tabular}{ccc}
\hline $\begin{array}{l}\text { Distance of monitoring point } \\
\text { from left wall }(\mathrm{m})\end{array}$ & $\begin{array}{c}\text { Stress distribution } \\
\text { along line-1 }(\mathrm{MPa})\end{array}$ & $\begin{array}{c}\text { Stress distribution } \\
\text { along line-3 (MPa) }\end{array}$ \\
\hline 0 & -0.25 & -0.01 \\
10 & -1.1 & -0.001 \\
20 & 2 & -3.55 \\
30 & 2.4 & -5.57 \\
40 & -2.1 & -1.57 \\
50 & -4.75 & -0.2 \\
60 & -5.1 & 1.2 \\
70 & -5.25 & -3.4 \\
80 & -1 & -4.8 \\
90 & -1.5 & -4.6 \\
\hline
\end{tabular}

Table 4. Stress distribution along the length of the bed at stain rate of $20 \mathrm{~mm} / \mathrm{s}$.

\begin{tabular}{lcc}
\hline $\begin{array}{l}\text { Distance of monitoring point } \\
\text { from left wall }(\mathrm{m})\end{array}$ & $\begin{array}{c}\text { Stress distribution } \\
\text { along line-1 (MPa) }\end{array}$ & $\begin{array}{c}\text { Stress distribution } \\
\text { along line-3 (MPa) }\end{array}$ \\
\hline 0 & -0.6 & -0.1 \\
10 & -0.7 & -0.08 \\
20 & 3.7 & -6.3 \\
30 & 2.9 & -6.51 \\
40 & -3.4 & -0.4 \\
50 & -7.8 & 0 \\
60 & -2 & 1.2 \\
70 & -1.5 & -7.5 \\
80 & 0.5 & -3.9 \\
90 & -2.8 & -3.6 \\
\hline
\end{tabular}


For mathematical analysis of fold pattern, a series of trigonometric function is formed, the sum of which gives a close fit to more complex function of the original curve. It is possible to represent the fold pattern in a summation series of sine functions:

$$
f(x)=a_{1} \sin \left(b_{1}+c_{1}\right)+a_{2} \sin \left(b_{2}+c_{2}\right)+\cdots
$$

Each set of values of $a, b$ and $c$ represents a unique fold pattern. The coordinates of monitoring points lying on line-3 is plotted and best fit curve (sum of trigonometric functions) is obtained for each case. The equation and R-square values are determined. The equation representing the folding pattern in this case is given by:

$$
\begin{aligned}
f(x)= & 494.8 \sin (0.00262 x+5.789) \\
& +134.7 \sin (0.005718 x+6.97) \\
& \{\text { R-square }=0.9985\} .
\end{aligned}
$$

To calculate the amplitude of the fold,

$$
d f(x) / d x=0
$$

and

$$
d^{2} f(x) / d x^{2}>0 .
$$

Equations (1) and (2) give the coordinate of hinge point in trough. For the purpose of analysis, the left most hinge is considered. Distance of hinge point below the symmetric axis represents the amplitude of the fold. The amplitude in this case is $0.842 \mathrm{~m}$.

The resistance force $\left(F_{\text {int }}\right)$ developed within the competent layer is given by:

$$
F_{\text {int }}=\frac{\left(2 \pi^{2} \mu d^{3} v_{x}\right)}{3 W_{i}^{2} e_{x}}
$$

where, $\mu$ is the viscosity coefficient of the rock, $d$ represents thickness, $W_{i}$ represents wavelength, $v_{x}$ represents shortening rate along the length and $e_{x}$ is bulk shortening.

The internal resistance force is determined by calculating the compressive force on the monitoring points along the left wall. The internal resistance

Table 5. Stress distribution along the length of the bed at compression rate of $50 \mathrm{~mm} / \mathrm{s}$.

\begin{tabular}{ccc}
\hline $\begin{array}{l}\text { Distance of monitoring point } \\
\text { from left wall }(\mathrm{m})\end{array}$ & $\begin{array}{c}\text { Stress distribution } \\
\text { along line-1 (MPa) }\end{array}$ & $\begin{array}{c}\text { Stress distribution } \\
\text { along line-3 (MPa) }\end{array}$ \\
\hline 0 & 0 & -0.2 \\
10 & 1 & -1.3 \\
20 & 1.5 & -2.6 \\
30 & 3.25 & -6.9 \\
40 & -3 & -0.8 \\
50 & -18.67 & -0.3 \\
60 & -2.5 & 1.6 \\
70 & -0.8 & -8.3 \\
80 & 1.5 & -5.6 \\
90 & -2 & -5.8 \\
\hline
\end{tabular}

Table 6. Stress distribution along the length of the bed at compression rate of $70 \mathrm{~mm} / \mathrm{s}$.

\begin{tabular}{lcc}
\hline $\begin{array}{l}\text { Distance of monitoring point } \\
\text { from left wall }(\mathrm{m})\end{array}$ & $\begin{array}{c}\text { Stress distribution } \\
\text { along line-1 (MPa) }\end{array}$ & $\begin{array}{c}\text { Stress distribution } \\
\text { along line-3 (MPa) }\end{array}$ \\
\hline 0 & 0 & -0.2 \\
10 & 1.6 & -0.1 \\
20 & 2.2 & -2.7 \\
30 & 0.6 & -3.2 \\
40 & -4.7 & -4 \\
50 & -21.36 & -0.5 \\
60 & -2.2 & 15 \\
70 & 2 & -87 \\
80 & 1.5 & -6 \\
90 & -2 & 5 \\
\hline
\end{tabular}


Table 7. Stress distribution along the length of the bed at compression rate of $100 \mathrm{~mm} / \mathrm{s}$.

\begin{tabular}{ccc}
\hline $\begin{array}{l}\text { Distance of monitoring point } \\
\text { from left wall }(\mathrm{m})\end{array}$ & $\begin{array}{c}\text { Stress distribution } \\
\text { along line-1 }(\mathrm{MPa})\end{array}$ & $\begin{array}{c}\text { Stress distribution } \\
\text { along line-3 (MPa) }\end{array}$ \\
\hline 0 & -0.4 & -0.1 \\
10 & -0.7 & 0 \\
20 & -2.1 & 0.4 \\
30 & -2.5 & 0.6 \\
40 & -1.8 & 1.5 \\
50 & -9.2 & -0.5 \\
60 & 0.5 & 0.5 \\
70 & 1.5 & -4.8 \\
80 & 0.95 & -2.2 \\
90 & -0.9 & -3.3 \\
\hline
\end{tabular}

force developed at a compression rate of $1 \mathrm{~mm} / \mathrm{s}$ is $0.25 \mathrm{MPa}$.

The qualitative analysis of compressive and tensile stress is shown in figure 7 . For quantitative analysis, stress level at each monitoring point on line- 1 and line- 3 is calculated (figure 5). The stress values

$(+\mathrm{ve})$-Tensile stress (-ve)-Compressive stress

at various monitoring points are given in tables $3-$ 7. The inflection points along line- 1 are represented by a, b, c, d and that along line- 3 are represented by $a_{1}, b_{1}, c_{1}, d_{1}$. Thus, region $a-b$ or $a_{1}-b_{1}$ represents region between the first and second inflection points in the bed. To correlate the study of stress distribution and situation of the bed, same nomenclature is followed in stress distribution curve also. Locations of these points are mentioned in the plot of stresses in each case (tables 4, 5, 6 and 7).

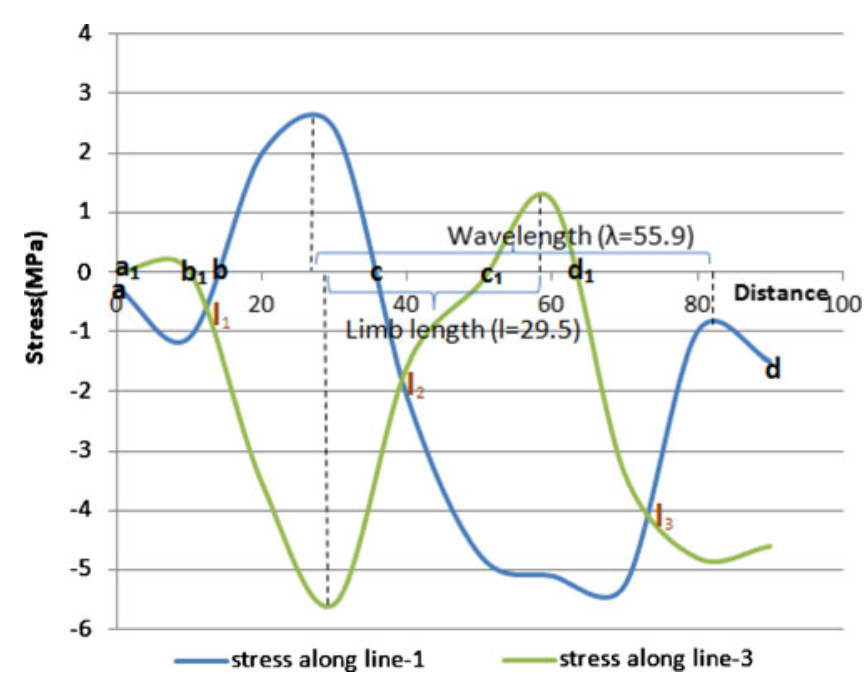

Figure 8. Plot of stress distribution along the length of the bed at compression rate of $1 \mathrm{~mm} / \mathrm{s}$.
Figure 8 indicates the distribution of stresses along the length of the bed. Along line-1, the region $\mathrm{a}-\mathrm{b}$ and $\mathrm{c}-\mathrm{d}$ are under compression and $\mathrm{b}-\mathrm{c}$ is in tension. Along line-3, the region $b_{1}-c_{1}$ is in compression and $\mathrm{a}_{1}-\mathrm{b}_{1}$ and $\mathrm{c}_{1}-\mathrm{d}_{1}$ are under tension. The region in compression lie on concave side of the fold and that under tension lies on convex side of the fold (figure 7). The stress distribution curve along line- 1 and line- 3 are opposite in nature due to lengthening and shortening phenomenon on either sides. In the zone where line-1 curve shows compressive nature, line-3 curve has tensile nature. The local maxima of compression of line-1 curve lies approximately opposite to the local maxima of tension of line- 3 which is also logical, since the region where line- 1 has concave curvature, line-3 has convex curvature (figure 8 ). The point where stress curves of line- 1 and line- 3 intersect represents the zone of uniform stress along the thickness of the bed. At this point, the concavity of fold reverses, known as inflection point (I) of the fold. The local maxima of tension along line-3 represents crest in the fold. Therefore, distance between two consecutive local maxima of tension along horizontal direction represents wavelength of the fold (figure 8). The distance along horizontal axis between consecutive local maxima of tension and

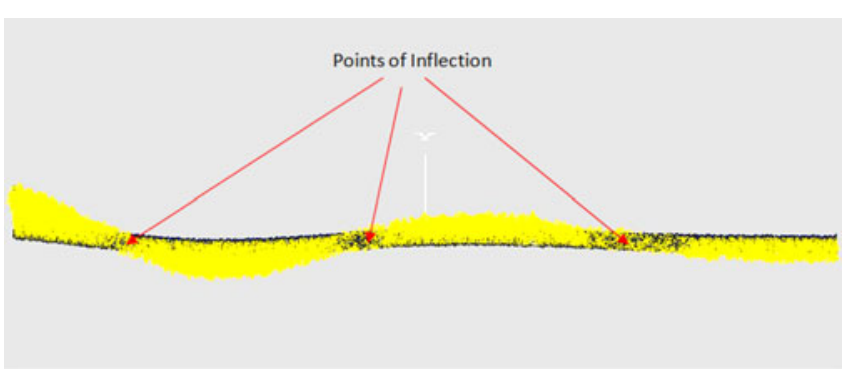

Figure 9. Displacement vectors of particles and points of inflection generated in shale layer at compression rate of $1 \mathrm{~mm} / \mathrm{s}$. 
local maxima of compression represent limb length. Wavelength and limb length is calculated from the plots.

In this model, only the left wall is moved. The stress is transmitted from the left wall to the shale bed which travels along the bed to the right wall. Most of the energy is being consumed in deforming the left portion of the bed. Thus, the amplitude of fold decreases and the linear distances between the consecutive inflection points $\left(\mathrm{I}_{1}, \mathrm{I}_{2}, \mathrm{I}_{3}\right.$, etc.) increases going from left to right margin.

The net displacement of each particle with respect to their original position is shown in figure 9 . In order to analyze the variation of amplitude with rate of compression, the displacement of particles on the leftmost trough is considered. The monitoring point numbered 113 is lying in proximity of hinge point of leftmost trough. Therefore, the displacement of this point is calculated in order to obtain amplitude of the trough. The amplitudes of the trough wavelength and limb lengths are given in table 8 .

\subsection{Folding pattern when left wall is moved at the rate of $20 \mathrm{~mm} / \mathrm{s}$}

At compression rate of $20 \mathrm{~mm} / \mathrm{s}$, a horizontal stress of $0.6 \mathrm{MPa}$ is applied by the wall on the bed. The

Table 8. Values of parameters representing fold pattern at various compression rates.

\begin{tabular}{lr}
\hline Parameter & Values \\
\hline At $1 \mathrm{~mm} / \mathrm{s}$ & \\
Bulk shortening (\%) & 0.21 \\
Wavelength (m) & 55.9 \\
Length of limb (m) & 29.5 \\
Amplitude (m) & 0.842 \\
At 20 mm/s & \\
Bulk shortening (\%) & 0.30 \\
Wavelength (m) & 55.6 \\
Length of limb (m) & 32.6 \\
Amplitude (m) & 1.01 \\
At 50 mm/s & \\
Bulk shortening (\%) & 0.46 \\
Wavelength (m) & 50.95 \\
Length of limb (m) & 28.7 \\
Amplitude (m) & 1.047 \\
At 70 mm/s & \\
Bulk shortening (\%) & 0.6 \\
Wavelength (m) & 21.5 \\
Length of limb (m) & 1.176 \\
Amplitude (m) & \\
At 100 mm/s & 0.92 \\
Bulk shortening (\%) \\
Wavelength (m) \\
Length of limb (m) \\
Amplitude (m) & 41.5 \\
\hline
\end{tabular}

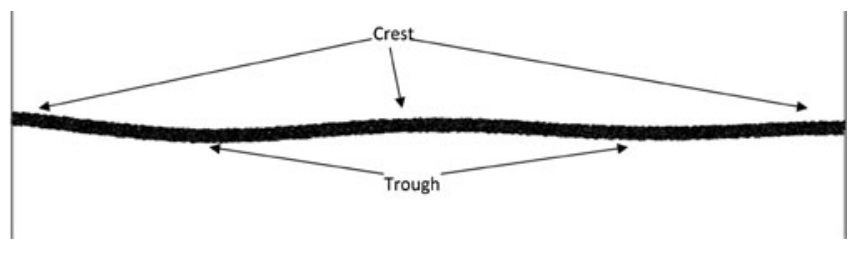

Figure 10. Fold pattern in shale bed with no initial geometric perturbation at compression rate of $20 \mathrm{~mm} / \mathrm{s}$.

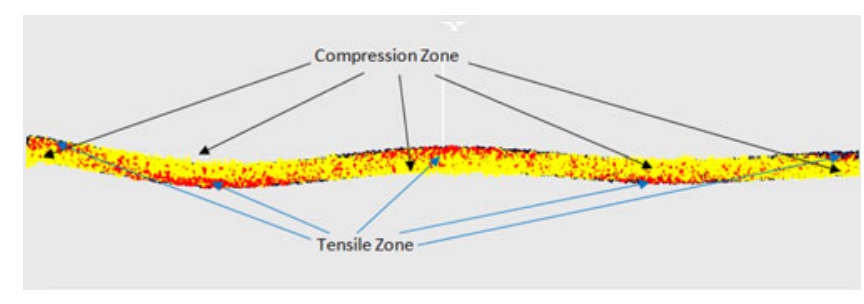

Figure 11. Distribution of compressive and tensile zone along the length of the bed at compression rate of $20 \mathrm{~mm} / \mathrm{s}$.

balls near the left wall are displaced by $0.3 \mathrm{~m}$. Therefore, a bulk shortening of $0.30 \%$ is obtained. The pattern of fold thus obtained is shown in figure 10. It is clear from the figure that with the increase in compression rate, the undulations in the bed increase resulting into formation of three crests and two troughs.

The equation governing the folding pattern at $20 \mathrm{~mm} / \mathrm{s}$ is given by:

$$
\begin{aligned}
& f(x)=78.14 \sin (0.000763 x+1.249) \\
& +10.3 \sin (0.01005 x-1.683) \\
& \{\mathrm{R} \text {-square }=0.9915\} .
\end{aligned}
$$

The amplitude for this case is $1.01 \mathrm{~m}$.

On further increasing the compression rate, redistribution of stress in the bed occurs, thereby forming more number of compression and tensile zones (figure 11).

Figure 12 shows that along line- 1 , regions $\mathrm{a}-\mathrm{b}$, $\mathrm{c}-\mathrm{d}$ and $\mathrm{e}-\mathrm{f}$ are under compression and $\mathrm{b}-\mathrm{c}$ and $\mathrm{d}-\mathrm{e}$ are under tension. Along line- 3 , the regions $\mathrm{b}_{1}-$ $c_{1}$ and $d_{1}-e_{1}$ are in the compression and $a_{1}-b_{1}$ and $\mathrm{c}_{1}-\mathrm{d}_{1}$ are under the tension. This plot also indicates that the stress curve along line- 1 is opposite in nature to that along line- 3 . The tensile stress is higher at hinge point in left trough as compared to other hinge point which denotes high curvature of left trough. Wavelength and limb length are calculated from plot (table 8).

\subsection{Folding pattern when left wall is moved at the rate of $50 \mathrm{~mm} / \mathrm{s}$}

At compression rate of $50 \mathrm{~mm} / \mathrm{s}$, a horizontal stress of $1.125 \mathrm{MPa}$ is applied by the wall. The 


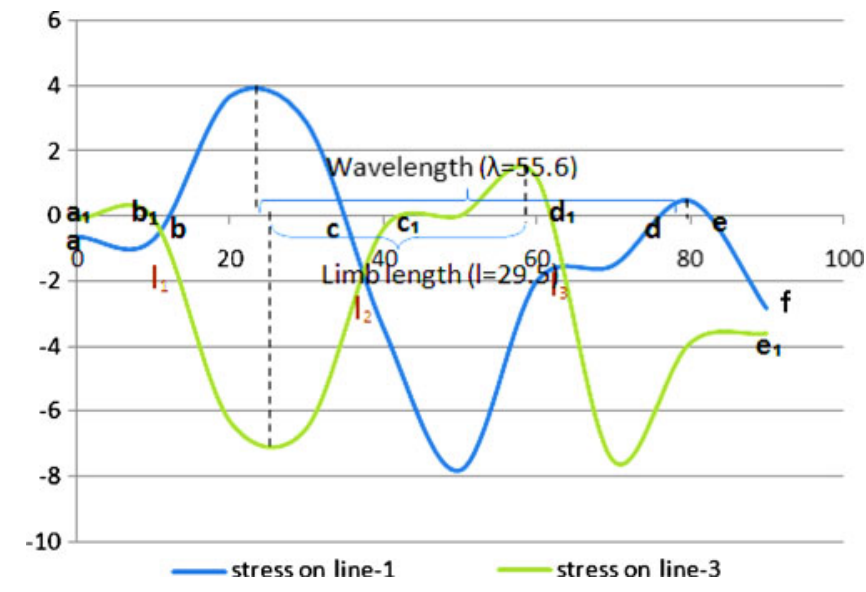

Figure 12. Plot of stress distribution along the length of the bed at compression rate of $20 \mathrm{~mm} / \mathrm{s}$.

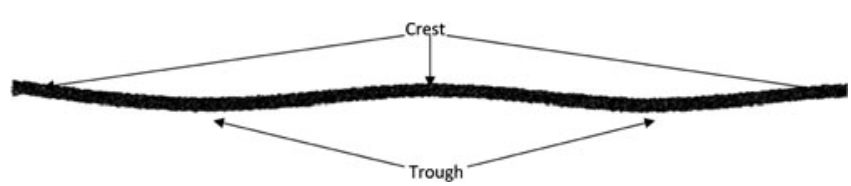

Figure 13. Fold development in shale bed with no initial geometric perturbation at compression rate of $50 \mathrm{~mm} / \mathrm{s}$.

horizontal displacement of balls close to left wall is $0.46 \mathrm{~m}$ thereby causing a bulk shortening of $0.46 \%$ (figure 13). Here the number of crest and troughs remains same as in the previous cases but their amplitudes have increased.

The equation governing the folding pattern at $50 \mathrm{~mm} / \mathrm{s}$ is given by:

$$
\begin{gathered}
f(x)=657.6 \sin (0.00008725 x+8.777) \\
+5.661 \sin (0.01707 x-2.475) \\
\{\text { R-square }=0.975\}
\end{gathered}
$$

The amplitude for this case is $1.047 \mathrm{~m}$.

The number of compression and tensile zone remains same but the stress level further increases (figure 14).

Figure 15 demonstrates that along line-1, regions $\mathrm{a}-\mathrm{b}$ and $\mathrm{c}-\mathrm{d}$ are under tension and $\mathrm{b}-\mathrm{c}$ and $\mathrm{d}-\mathrm{e}$ are under compression. Along line-3, the region $\mathrm{b}_{1}-\mathrm{c}_{1}$ and $\mathrm{d}_{1}-\mathrm{e}_{1}$ are in tension while $\mathrm{a}_{1}-\mathrm{b}_{1}$ and $\mathrm{c}_{1}-\mathrm{d}_{1}$ are under compression. Stress curve along line- 1 is opposite in nature to that of line-3. Wavelength and limb length are calculated from plot and are given in table 8 .

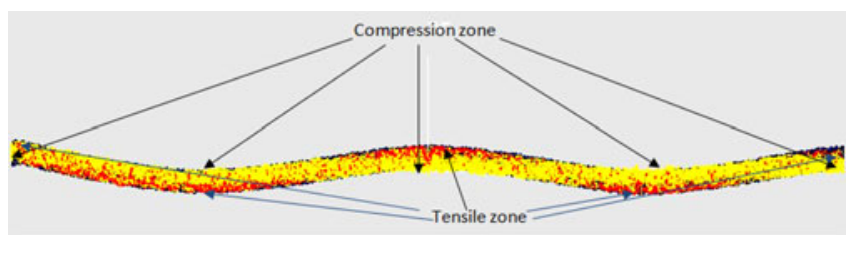

Figure 14. Distribution of compressive and tensile zones along the length of the bed at compression rate of $50 \mathrm{~mm} / \mathrm{s}$.

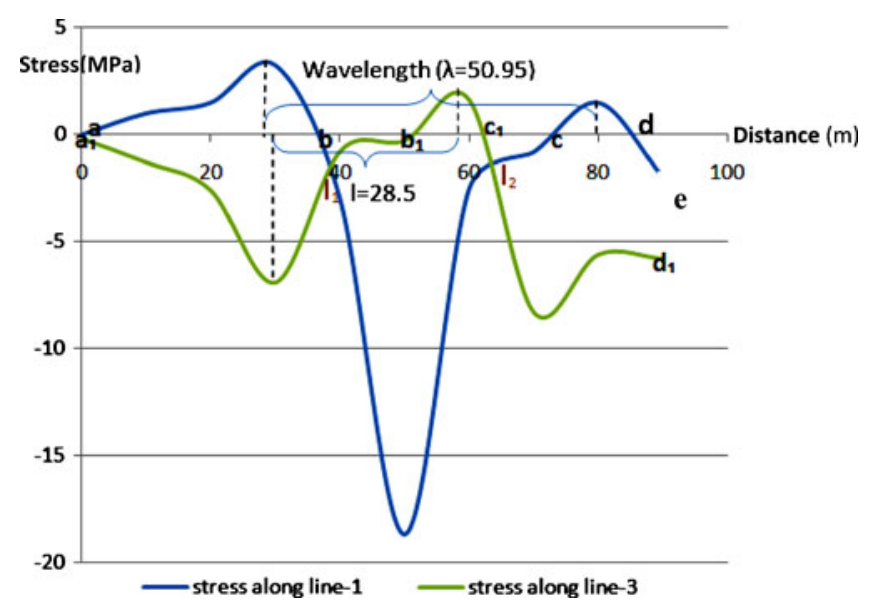

Figure 15. Plot of stress distribution along the length of the bed at compression rate of $50 \mathrm{~mm} / \mathrm{s}$.

\subsection{Folding pattern when left wall is moved at the rate of $70 \mathrm{~mm} / \mathrm{s}$}

A horizontal stress of $1.47 \mathrm{MPa}$ is applied on the wall at a rate of $70 \mathrm{~mm} / \mathrm{s}$. There is breakage of bonds at the points of maximum curvature leading to the formation of cracks at hinge point. The wavelength decreases and the amplitude increases leading to the formation of more prominent and well developed folding pattern (figure 16).

The equation governing the folding pattern at $70 \mathrm{~mm} / \mathrm{s}$ is:

$$
\begin{gathered}
f(x)=416 \sin (0.00007758 x+8.298) \\
+7.803 \sin (0.01426 x+5.69) \\
\{\text { R-square }=0.9896\} .
\end{gathered}
$$

The amplitude for this case is $1.176 \mathrm{~m}$.

There is an appreciable change in the stress distribution pattern along the bed (figure 17). The stress on the balls lying in the proximity of cracks has decreased manifold. The strain energy accumulated due to folding is responsible to form cracks. 


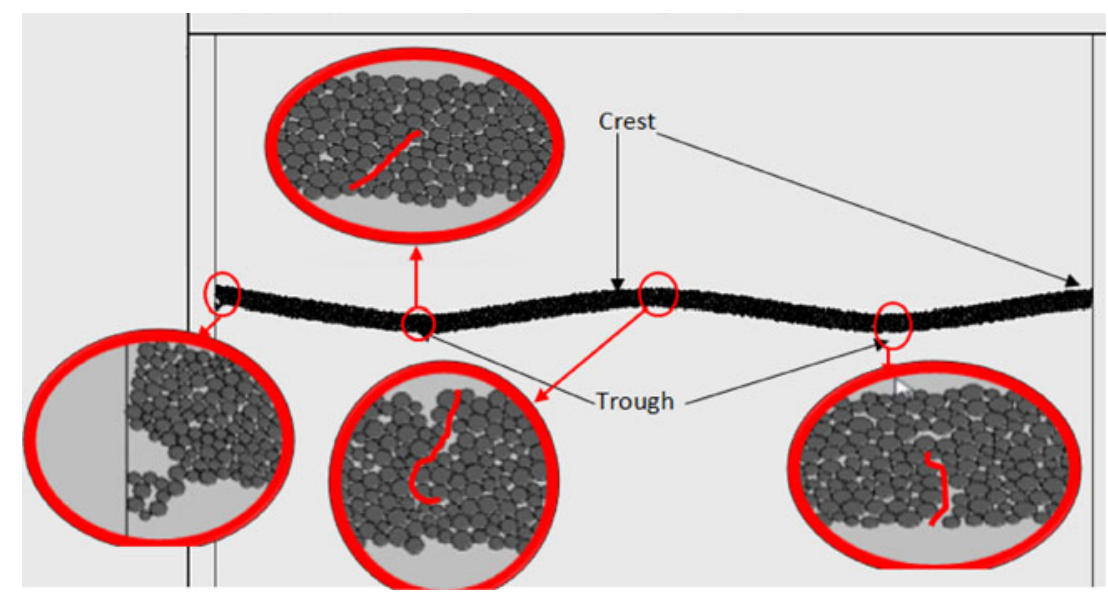

Figure 16. Fold development in shale bed with no initial geometric perturbation at compression rate of $70 \mathrm{~mm} / \mathrm{s}$.

Figure 18 exhibits the stress distribution curve along line-1 which is deviating from the earlier trend and the regions $\mathrm{a}-\mathrm{b}$ and $\mathrm{c}-\mathrm{d}$ are under tension and $\mathrm{b}-\mathrm{c}$ and $\mathrm{d}-\mathrm{e}$ are under compression. The curve along line-1 should have started from compression as in the cases above. But in this case, as a result of high compression rate there are fractures in the bed (figure 16). The edge on the left side of the bed has failed resulting into breakage of contact bonds. Thus, this part is showing zero stress in the plot (figure 18). Moving ahead along the curve in $\mathrm{a}-\mathrm{b}$ region, the hinge point should have shown high tensile stress, but there is a tensile crack at the hinge point resulting in relaxation in stress. Similar is the reason for low tensile stress level in $c-d$ region. Along line- 3 , the region $b_{1}-c_{1}$ and $\mathrm{d}_{1}-\mathrm{e}_{1}$ are in tension and $\mathrm{a}_{1}-\mathrm{b}_{1}$ and $\mathrm{c}_{1}-\mathrm{d}_{1}$ are under compression. The curve starts from zero stress as the upper portion of the bed in the left side leaves contact with the wall during the process of folding and thus gets unstressed. Fractures in bed are also a reason for low compressive stress level in $a_{1}-b_{1}$ region. There is a peak of compression in region $c_{1}-d_{1}$, because the tensile crack is only in lower part of the bed. The upper part is intact

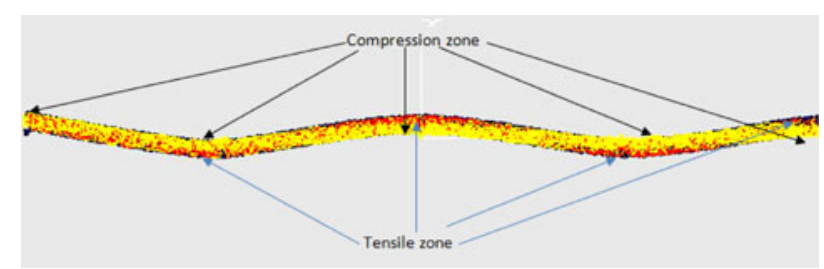

Figure 17. Distribution of compressive and tensile zones along the length of the bed at compression rate of $70 \mathrm{~mm} / \mathrm{s}$. and at such high compression rate highly intense compressive zone is formed (figure 16). Although, the opposite nature of stress curve along line- 1 and along line-3 is maintained; wavelength and limb length are calculated from the plot (table 8) in this case also.

\subsection{Folding pattern when left wall is moved at the rate of $100 \mathrm{~mm} / \mathrm{s}$}

When the compression rate is $100 \mathrm{~mm} / \mathrm{s}$, a horizontal stress of $1.99 \mathrm{MPa}$ is applied on the wall. In this case, bulk shortening of $0.92 \%$ and highly fractured fold pattern is formed (figure 19). Failure of bed has taken place in both tension and compression modes. The loci of failure are the points

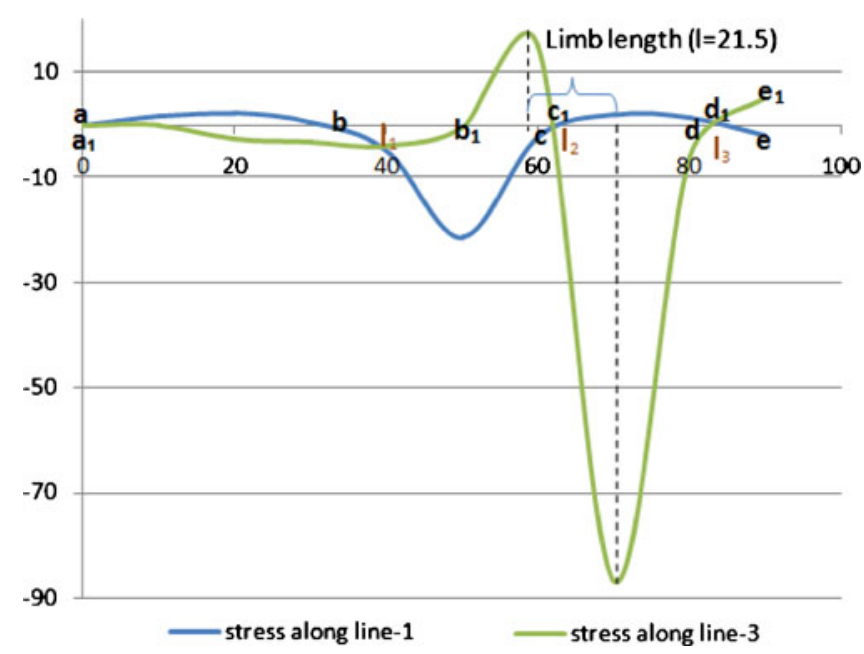

Figure 18. Plot of stress distribution along the length of the bed at compression rate of $70 \mathrm{~mm} / \mathrm{s}$. 


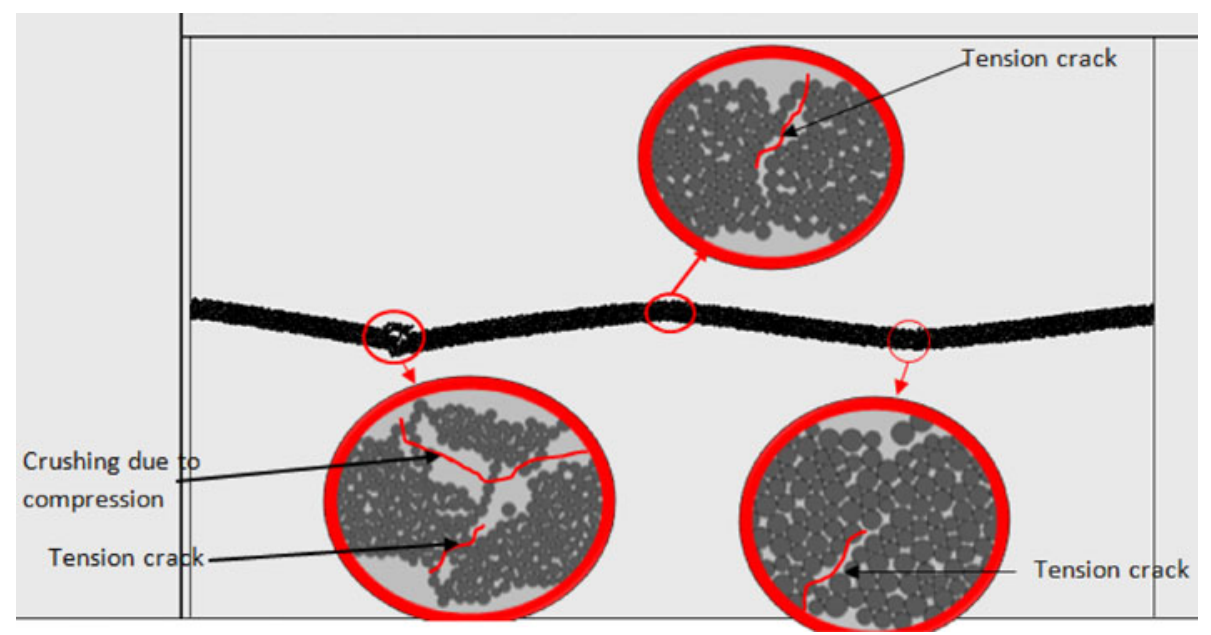

Figure 19. Fold development in shale bed with no initial geometric perturbation at compression rate of $100 \mathrm{~mm} / \mathrm{s}$.

where the curvature is maximum which is present in the form of peak of crest and trough. There is no change in number of crests and troughs but their amplitudes have increased.

The equation governing the folding at $100 \mathrm{~mm} / \mathrm{s}$ is given by:

$$
\begin{aligned}
f(x)= & 537.9 \sin (0.000145 x+6.961) \\
+ & 29 \sin (0.007592 x+5.18) \\
& \{\mathrm{R} \text {-square }=0.989\} .
\end{aligned}
$$

The amplitude for this case is $2.001 \mathrm{~m}$. Because of high compression rate $(100 \mathrm{~mm} / \mathrm{s})$, fractures have developed in the bed (figure 20).

Figure 21 shows that on stress distribution curve along line- 1 , regions $\mathrm{a}-\mathrm{c}$ and $\mathrm{d}-\mathrm{e}$ are under compression and $\mathrm{c}-\mathrm{d}$ is in tension. The curve along line- 1 is starting from non-zero value, which shows that the broken left edge is bearing some of the load (figure 19). The curve is not following the conventional trend because of fractures in the bed. Conventionally, the region $\mathrm{a}-\mathrm{b}$ of curve should be in tension but in this case it is in compression; this is because of failure at the hinge point in left trough. The lower part breaks in tension, resulting in tensile cracks and the upper part of the bed

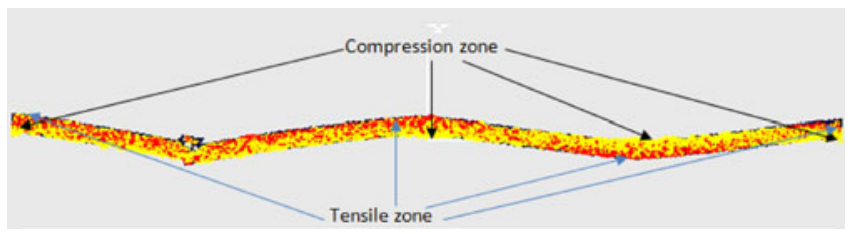

Figure 20. Distribution of compressive and tensile zones along the length of the bed at compression rate of $100 \mathrm{~mm} / \mathrm{s}$. breaks due to compression. The crushing of particles in the upper half validates the compressive failure. After the failure of bed at this hinge point, the two parts slides past one another resulting into shearing movement due to differential stress levels. In region $\mathrm{b}-\mathrm{c}$, the bed failure is restricted to upper half and the compressive stresses are maintained in lower half. In region $\mathrm{c}-\mathrm{d}$, there are newly developed cracks resulting in less intense tensile stresses. Along line- 3 , the regions $b_{1}-c_{1}$ and $d_{1}-f_{1}$ are in compression and $\mathrm{a}_{1}-\mathrm{b}_{1}$ and $\mathrm{c}_{1}-\mathrm{d}_{1}$ are under tension. The curve starts from zero stress as discussed in previous condition. Since, the bed is broken at the hinge of left trough, the two sides slip over one another causing compression in lower half and tension in the upper. The sliding of two sides results in the formation of fault in the shale bed. In region $b_{1}-c_{1}$, the curve shows abrupt change in stress from tensile to compressive. This is the cause

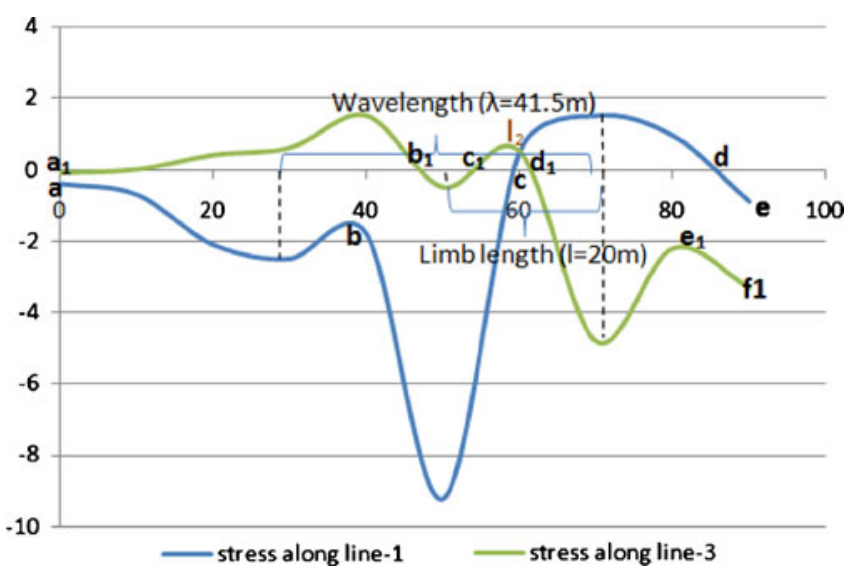

Figure 21. Plot of stress distribution along the length of the bed at compression rate of $100 \mathrm{~mm} / \mathrm{s}$. 


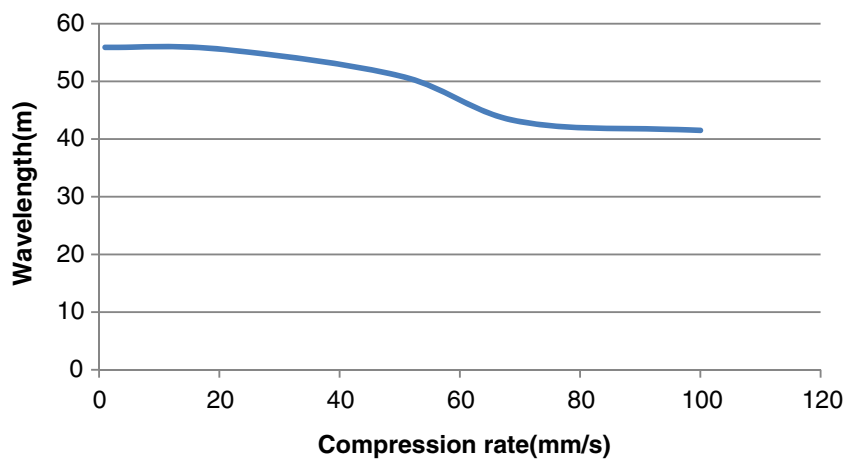

Figure 22. Plot of wavelength vs. compression rate.

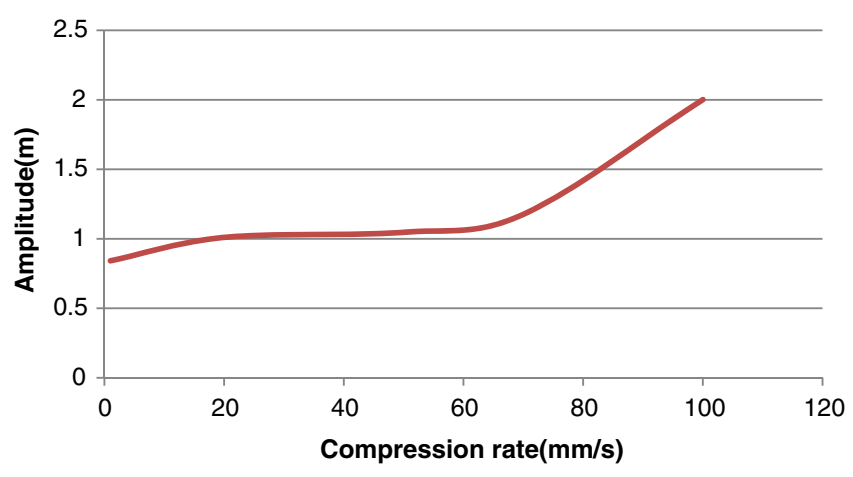

Figure 23. Plot of amplitude vs. compression rate.

of failure at the hinge of the crust. Between $c_{1}$ and $\mathrm{e}_{1}$ curve follows conventional behaviour. In region $\mathrm{e}_{1}-\mathrm{f}_{1}$, the bed edge breaks resulting into compressive stress and then into conventional tensile stress. The opposing nature of stress curve along line-1 and that along line-3 is continued in this case also. Wavelength and limb length are calculated from plot and given in table 8 . The compression rate variation with wavelength and amplitude is shown in figures 22 and 23. It is clearly visible that after a compression of $60 \mathrm{~mm} / \mathrm{s}$, the behaviour of material changed drastically. The wavelength decreased from 50 to $43 \mathrm{~m}$, whereas amplitude showed an increasing trend and reached up to $1.5 \mathrm{~m}$.

This study makes it clear that there is a significant nonperiodic lateral change in wavelength. Although, the magnitude of asymmetry is not related to the folds in most geological situations, the folds away from the compressional stress side have the lower amplitude. This may be due to the scale effect of the model in terms of chosen dimension of competent geo-material layer with the high rate of compression. The fast transmission of stress from one end to the other may be one of the probable reasons to create low magnitude asymmetry - slight lateral or change in wavelength of the fold. A high asymmetric fold model incorporates other dimensions of research such as the degree of competence, friction between layers, etc., which form the basis for further research in this area and have been kept out of scope of the study.

\section{Conclusion}

The mechanics of folding at different compression rates have been studied using particle flow code. This paper demonstrates effects of different compression rates on $100 \mathrm{~m}$ long shaly bed, derived from detailed interpretation of stress distribution. The evolution of different folding patterns at different compressive forces as well as stress and displacement in folded shale bed along its entire length is presented and discussed in this paper. The results bring forth the locations of crests and troughs, points of inflection, wavelengths and pattern of folding, and stress concentration in various parts of the bed along with bulk shortening. The wavelength of fold decreases continuously with increasing rate of compression, for example, from $55.9 \mathrm{~m}$ at a compression rate of $1 \mathrm{~mm} / \mathrm{s}$ to $43 \mathrm{~m}$ at a rate of $70 \mathrm{~mm} / \mathrm{s}$. The number of inflection points increases from 3 to 4 with increases in compression rate from 1 to $20 \mathrm{~mm} / \mathrm{s}$, thereafter the number of inflection points remains constant but the amplitude of crest and trough increases. At low compression rate of $20 \mathrm{~mm} / \mathrm{s}$, conventional stress distribution takes place in the bed in which the part on convex side is under tension whereas the part on the concave side is under compression. At high rate of compression $(>70 \mathrm{~mm} / \mathrm{s})$, the pattern of stress distribution changes. At the hinge point on convex side, where failure of bed takes place, tensile stresses convert to compressive stresses and limbs on either side slides over one another resulting into initiation of faulting. With increasing compression rate, the total shortening also increases resulting into more prominent folds. Bulk shortening reaches its critical value at $0.60 \%$ beyond which the rupture starts propagating in the bed resulting in formation of faults and relaxation of stresses takes place reducing the amplitude of crust and trough. PFC is a very strong tool to simulate the real life problems and understand the mechanism of changes.

\section{References}

Biot M A 1959 On the instability of folding deformation of a layered viscoelastic medium in compression; J. Applied Mechanics 26 393-400.

Biot M A 1961 Theory of folding of stratified viscoelastic media and its implications in tectonics and orogenesis; Geol. Soc. Am. Bull. 72 1595-1620. 
Biot M A, Odé H and Roever W L 1961 Experimental verification of the theory of folding of stratified visco-elastic media; Geol. Soc. Am. Bull. 72 1621-1632.

Carreras J 2001 Zooming on Northern cap de Creus shear zones; J. Struct. Geol. 23 1457-1486.

Chekhov V N 1975 Effect of a tracking load on the fold formation in the Earth's crust; Prikl. Mekh 11 86-92.

Cundall P A and Strack O D L 1979 A discrete numerical model for granular assemblies; Géotechnique $\mathbf{2 9}$ 47-65.

Enrique G R and Griera A 2011 Strain rate influence on fracture development in experimental ductile multilayers; Tectonophys. 502 351-363.

Fletcher R C 1977 Folding of a single viscous layer: Exact infinitesimal-amplitude solution; Tectonophys. 39 593606.

Fletcher R C 1979 The shape of single-layer folds at small but finite amplitude; Tectonophys. 60 77-87.

Ghosh S K 1993 Structural Geology; Prentice Hall.

Guz A N and Chekhov V N 1975 Linearized theory of fold formation in the Earth's crust; Prikl. Mekh 11 $1-17$.
PFC2D (Particle Flow Code in 2 Dimensions), Version 1.1. Itasca Consulting Group, Inc. 1999, Minneapolis, MN: ICG.

Ramberg H 1963 Strain deformation and geometry of folds; Bull. Geol. Inst., Univ. Uppsala 42 1-20.

Schopfer M P J and Zulauf G 2002 Strain dependent rheology and the memory of plasticine; Tectonophys. 354 85-99.

Schueller S, Gueydan F and Davy P 2005 Brittle ductile coupling role of ductile viscosity on brittle fracturing; Geophys. Res. Lett. 32 L1038, doi: 10.1029/2004 GL022272.

Smith R B 1975 Unified theory of the onset of folding, boudinage and mullion structure; Geol. Soc. Am. Bull. 86 1601-1609.

Smith R B 1977 Formation of folds, boudinage and mullions in non-Newtonian materials; Geol. Soc. Am. Bull. 88 $312-320$.

Smith R B 1979 The folding of a strongly non-Newtonian layer; Am. J. Sci. 279 272-287.

Von Kármán T and Tsien H S 1939 The buckling of spherical shells by external pressure; J. Aeronaut. Sci. 43-50. 